\title{
Targeting migration with limited control: the case of the UK and the EU
}

\author{
Cinzia Rienzo ${ }^{1}$ and Carlos Vargas-Silva ${ }^{2^{*}}$
}

\author{
* Correspondence: \\ carlos.vargas-silva@compas.ox.ac.uk \\ ${ }^{2}$ Centre on Migration, Policy and \\ Society, University of Oxford, 58 \\ Banbury Road, Oxford OX2 6QS, UK \\ Full list of author information is \\ available at the end of the article
}

\begin{abstract}
Since 2010 the UK Government has aimed to reduce net-migration. The UK Government cannot restrict EEA migration, and it has focused instead on restricting non-EEA migration, including closing routes intended for non-EEA high-skilled workers. We identify a possible substitution effect in this context: restricting one type of migration may lead to an increase in an unrestricted type (i.e., 'balloon effect'). We present evidence which is consistent with this substitution effect for the case of high-skilled migrant workers in the UK. We also construct counterfactual estimates of the number of different types of migrant workers in the UK with pre-policies conditions.
\end{abstract}

JEL: F22; J24

Keywords: High-skilled workers; Balloon effect; Net migration; United Kingdom; European Union

\section{Introduction}

Between 1993 and 2013 the foreign-born population in the UK more than doubled from 3.8 million to around 7.8 million. During that same period, the foreign-born share of the population increased from $7 \%$ to $13 \%$ (Rienzo and Vargas-Silva 2014). Public opposition to more migration is high, and about three quarters of people in Britain consistently favor decreasing migrant inflows (Blinder 2014). Unsurprisingly, migration has become an increasingly important topic for British politicians.

One of the major promises of David Cameron during the 2010 General Election campaign was to decrease net migration to the UK from the 'hundreds of thousands' to the 'tens of thousands.' After the election the UK Government established a net migration (i.e., immigration - emigration) target of fewer than 100,000 migrants per year by the end of the parliament (i.e., 2015) as a key policy objective, and UK migration policy has since been focused on this goal.

Everyone entering or leaving the UK for twelve months or more counts towards that target, including British and other European Economic Area (EEA) nationals whose entry and exit the UK Government cannot restrict. Given the limitations for restricting EEA migration, the UK Government's efforts to reduce net migration are built around the restriction of inflows of non-EEA nationals and efforts to boost outflows of nonEEA nationals. These policies are likely to affect the size and composition of the UK migrant workforce and, in particular, the high-skilled migrant workforce. There is no route for low skilled labor migration to the UK from outside of the EEA. As such, the

(c) 2015 Rienzo and Vargas-Silva. This is an Open Access article distributed under the terms of the Creative Commons Attribution License (http://creativecommons.org/licenses/by/4.0), which permits unrestricted use, distribution, and reproduction in any medium, provided the original work is properly credited. 
UK Government has restricted and closed routes intended for skilled non-EEA workers in order to reduce net migration.

The latest provisional estimate of net migration to the UK for the year to September 2014 is 298,000 (Office for National Statistics 2015). It is now certain that the UK Government will not achieve the net migration target of 100,000 before the 2015 General Election as promised by Prime Minister David Cameron. Nonetheless, the recent policies of the UK Government to decrease net migration provide an excellent opportunity to gain lessons about the consequences of pursuing a migration target in a context in which discretionary power is limited given the presence of elements over which the Government has different levels of influence (e.g., EEA vs. non-EEA migrant workers). In this paper we explore those lessons. In particular, we explore the impact of the restrictions on different migrant groups in terms of numbers and skills composition. We place particular emphasis on the possible interaction between the restricted and unrestricted components of UK migration.

In addition to reducing the number of non-EEA high-skilled workers, restrictions on non-EEA high-skilled migration could have resulted in an increase in the number of high-skilled EEA workers in the UK. It is possible that recent UK Government policies had a 'balloon effect' on high-skilled migration, where squeezing it at one end (i.e., restricting the number of non-EEA high-skilled workers) led to an increased size at the other (i.e., inflating the number of EEA high-skilled workers). Employers may look to the EEA if they are not able to hire as many high-skilled workers as they would like from outside the EEA. Also, the reduction in the supply of non-EEA workers may create a vacuum in the labor market that could be filled by EEA workers. These workers could target the UK as a destination in response to the non-EEA migration restrictions or simply come for other reasons (e.g., Eurozone crisis) and have an easier time finding jobs in the UK.

The key goal of this article is to shed light on the consequences of the net migration target for high-skilled migration to the UK. The emphasis is on high-skilled migrant workers as this group is the most likely to be affected by the restrictions. However, we also explore impacts on the high/low skilled migrant worker ratio. The focus of this paper is on recent migrant workers (RMW) in the labor force, defined as those who have been in the UK for less than three years, rather than on the entire population of migrant workers in the UK. The former are more likely to be affected by the new migration policies.

This article places particular emphasis on three key questions:

- What was the likely impact of the migration restrictions on overall highskilled migration to the UK? The paper compares results for different types of high-skilled RMW (i.e., based on nationality groups) and with different definitions of a high-skilled RMW (i.e., based on educational levels and type of occupation).

- Is the evidence consistent with a high skilled 'balloon effect?' Evidence consistent with a 'balloon effect' would imply a marked decrease in the number of non-EEA high-skilled workers and an increase in the number of EEA high-skilled workers since 2011 when most government policies aimed to reduce net migration took effect. We present different counterfactual scenarios about the potential number of different groups of high-skilled RMW in the UK without the restrictions. 
These counterfactual scenarios are constructed by assuming a continuation of previous trends and by re-weighting the UK Labour Force Survey so that the post migration policy changes sample has similar characteristics to the pre-policy changes sample.

- How has the skilled composition of the UK recent migrant workforce changed since the establishment of the restrictions? We explore the skills composition of RMW and compare to those of previous cohorts, investigating if these changes are driven by the composition of particular migrant groups. We also provide several counterfactual estimates to examine if the new government policies may have affected the skills distribution of RMW.

\section{Background}

\subsection{The net migration target and related policies}

In 2010 the UK Government established a net migration target of fewer than 100,000 migrants per year. The purpose of the target and related policies was to "scale back net migration to the levels of the 1990s" (Home Office, 2010). The net migration target includes all migrants based on (expected) length of residence of 12 months or more in or out of the UK. Policies related to cutting net migration faced two challenges:

- The UK Government cannot restrict migration of EEA workers: European Union (EU) law protects the freedom of movement across Member States for EU workers. The EEA includes the EU countries plus Iceland, Liechtenstein and Norway and allows the latter three countries to be part of the EU's single labor market. Given the limitation in restricting EEA migration, decreasing non-EEA net migration has been the main focus of the UK Government during recent years.

- The UK Government cannot simply restrict the routes intended for low skilled labor migrants in order to achieve the net migration target: The UK Points Based System was originally envisioned as a five tier category system in which the Tier 3 category was designed as a route for low-skilled non-EEA nationals to enter the UK for work purposes. This route was never launched, and there is currently no route for low-skilled labor migration to the UK from outside of the EEA. The efforts to reduce non-EEA migration must involve cuts in migration routes intended for skilled non-EEA nationals.

The bulk of the restrictions on non-EEA migration to the UK came into effect during 2011. The main changes can be summarized into four broad categories (see Appendix for more details):

- Closing the Tier 1 general category, which was the main route for non-EEA highskilled labor migration to the UK without a job offer.

- Putting a cap on the Tier 2 general category, which is the main route for non-EEA migration to the UK for work reasons with a job offer.

- Adding restrictions to non-EEA student visas.

- Increasing the minimum income threshold for British nationals to bring non-EEA partners and children to the UK. 


\subsection{Direct impact of the policies}

It is challenging to present evidence of a direct link between policy changes and the inflow/outflow of migrants to/from the UK. Simultaneous changes in many other factors, such as economic conditions in the UK, are likely to impact the size of the migrant workforce. However, the impact of UK economic conditions and related factors are likely to affect all types of migrants (i.e., EEA and non-EEA nationals), while the direct impact of policy changes should be concentrated on the non-EEA group.

When the new UK Government policies were announced, each policy was accompanied by an impact assessment from the UK Home Office which included an estimation of the expected level of net migration after the introduction of the policy. The impact assessments can be used to determine the degree to which each policy was expected to reduce non-EEA migration. The UK Home Office impact assessments do not differentiate across skill groups, but, as explained above, high-skilled migration should account for a substantial portion of the reduction in total net migration.

Table 1 reports the expected reduction in net migration as a result of the new policies. The information on the impact assessments suggests that the total reduction in net migration was going to be 76,000 , distributed as 56,000 from the study route, 11,000 from the work route and 9,000 from the family route (Home Office 2011a; 2011b; 2012). The final estimate of net migration for 2010 was 256,000. Hence, everything else constant, the expected level of net migration after the policies, according to the information on the impact assessments, would be 180,000. This is an expected reduction of $30 \%$ but still falls short of the 100,000 net migration target.

\subsection{Indirect impact of the policies}

In practice, not everything remains constant after the imposition of additional migration restrictions. There is the possibility that policies directed at one group of migrants indirectly affect another group. As explained above, there could be a 'balloon effect' in which restrictions in one type of migration lead to an increase in another type which cannot be restricted. Figure 1 summarizes the possible interactions between the restrictions on non-EEA migration and EEA migration to the UK.

Restricting the access of non-EEA nationals to UK labor markets could be seen as a way of encouraging the recruitment of British workers on the part of employers. While it is likely that some of this recruitment occurs in practice, high-skilled work often involves a lengthy training period and the supply of high-skilled British workers is unlikely to increase much in the short-run (i.e., inelastic supply of high skilled labor in the short-run). The unmet demand for high-skilled workers may lead to more

Table 1 Expected direct impact of the policies on net migration

\begin{tabular}{llllll}
\hline Estimate & \multicolumn{4}{c}{ Route } & \\
\cline { 5 - 5 } & & Study & Work & Family & Total \\
\hline Final number for 2010 & (A) & & & 256,000 \\
IA expected reduction & (B) & 56,000 & 11,000 & 9,000 & 76,000 \\
Expected final number & (C = A - B) & & & 180,000 \\
\hline Note: IA = Impact Assessment from the UK Home Office. The impact assessments are: Home Office 2011a; 2011b; 2012.
\end{tabular}

Note: IA = Impact Assessment from the UK Home Office. The impact assessments are: Home Office 2011a; 2011 b; 2012. 


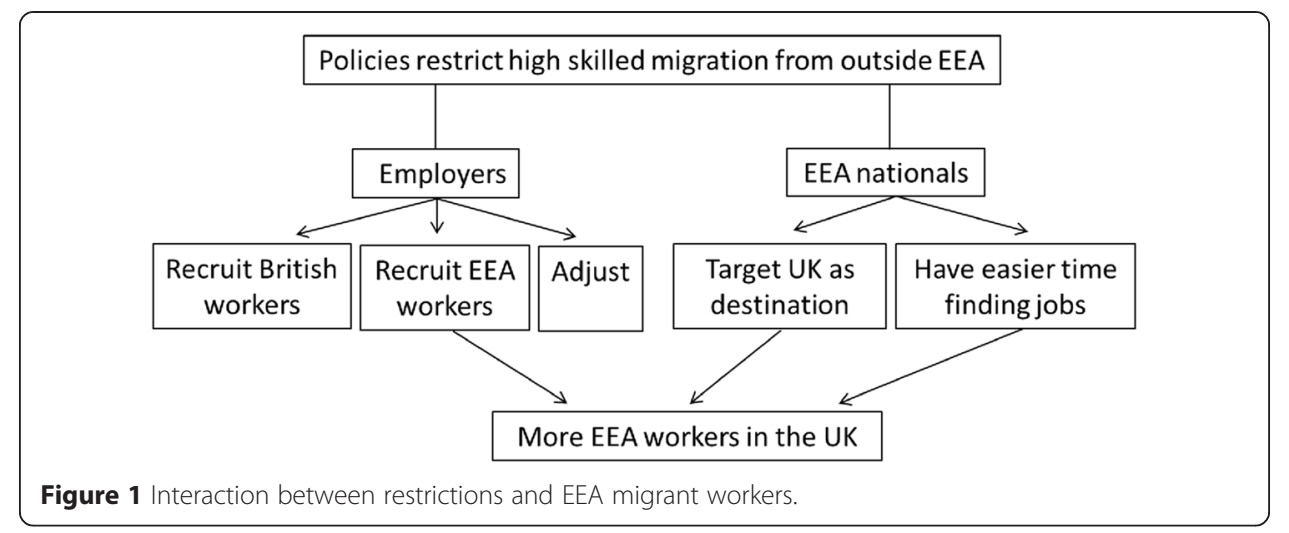

recruitment from the bigger pool of EEA high-skilled nationals, many of whom are ready to take on the new positions on a short notice. A third possibility would be for employers to adjust to the shortage of high-skilled workers. For instance, employers could up-skill current workers or change the production process to make less use of high skilled labor (Ruhs and Anderson 2010). This response would not increase the demand for high skilled EEA nationals.

In a survey of more than 1,000 UK employers conducted as migration restrictions were getting underway in 2011, 18\% of employers said that they intended to respond to the government's new non-EEA migration restrictions by recruiting more UK graduates, and $23 \%$ indicated that they planned to up-skill existing workers. Meanwhile, 34\% of employers suggested that they intended to recruit more EEA migrant workers in response to the restrictions (Chartered Institute of Personnel and Development 2011).

In a follow-up survey in the summer of 2014, 20\% of the employers affected by the migration restrictions said that they actually recruited more EEA workers in response to the government policies on non-EEA migration (Chartered Institute of Personnel and Development 2014). There is also evidence from sectors such as social work that some degree of substitution has actually occurred (Hussein 2014). Other research has suggested that substitution of non-EEA migrant workers for EEA migrant workers is not straightforward given differences in experience, formal qualifications, cultural attributes, language skills and tendency to look for work in particular industries (Bach 2010; Migration Advisory Committee 2012; Scullion and Pemberton 2010, 2015).

The reduction in the supply of high-skilled non-EEA workers may also make it easier for EEA nationals to find jobs in the UK. Some EEA nationals may target the UK as a destination in response to the non-EEA migration restrictions if they feel that they now have a better chance of finding a job. However, it is likely that most EEA nationals come to the UK for other reasons, such as escaping from the negative economic effects of the recent Eurozone crisis and just have an easier time finding jobs in the UK than it would otherwise be the case without the restrictions.

The possibilities mentioned above are not mutually exclusive. For instance, some employers may recruit more UK graduates and EEA nationals. As such, even if there is an increase in the number of EEA workers in response to a reduction in the number of 
non-EEA workers, it is not clear that the size of the balloon (i.e., size of the recent migrant workforce) will remain the same. The increase in EEA workers is likely to only partially compensate for the reductions in non-EEA workers.

\section{Data and definitions}

The main data source used to construct UK immigration, emigration and net migration estimates is the International Passenger Survey. Available data on arriving migrants to the UK from the International Passenger Survey does not include measures of skills. One alternative is to examine the number of high-skilled RMW using the UK Labour Force Survey.

The UK Labour Force Survey is conducted by the UK Office for National Statistics, and it is the largest household survey in the country. It includes over 50,000 individuals every quarter, and it is designed to be representative of the working age population of the whole country. The analysis below uses UK Labour Force Survey data for the fourth quarter of each year (i.e., 2007 to 2013). By comparing each quarter to the same quarter of previous years, the analysis controls for the potential effect of seasonal changes in the data.

RMW are defined as individuals born outside the UK who are not UK nationals, have been in the UK for less than three years, are currently in employment (defined as employees, self-employed, working for a family business or working under a government scheme) and are of working age (16-65 years of age for males, 16-61 years of age for females).

The analysis presents further distinctions based on nationality in order to test the validity of the 'balloon effect' hypothesis. The focus is on two groups: non-EEA and Old EU. Non-EEA RMW refers to those who are nationals of countries which are not members of the EEA. Migrants from these countries need a permit to work in the UK. We exclude Switzerland, a non-EEA country, from this group given that Swiss nationals do not need a permit to work in the UK. Old EU RMW refers to those who are nationals of the 14 other countries that were members of the EU before 2004. Nationals of the Old EU countries have been able to enter and work in the UK without restrictions for a long time.

In addition to Old EU nationals, it could be possible to include in the analysis nationals of the countries which have joined the EU since 2004 (i.e., 'accession countries' or 'new EU member states'). A large part of the debate on migration to the UK over the last decade has centered on the decision to provide unrestricted access to UK labor markets to nationals of the new EU member states immediately after accession (Dustmann and Frattini 2014; Lemos and Portes 2013). Migrants from new EU member states in the UK come mostly for work reasons and have higher employment rates than Old EU and British nationals (Clark and Drinkwater 2014; Drinkwater and Robinson 2013). However, our preliminary data analysis suggests that while many migrants from these accession countries have relatively high-levels of education, they tend to work mostly in low skilled occupations and earn low wages. For instance, while $58 \%$ of Old EU and $47 \%$ of non-EEA highly educated RMW were in top occupations for the period of interest, this number is just $7 \%$ for those RMW from the new EU member states. Likewise, Old EU and non-EEA highly educated RMW earned an estimated $£ 29,000$ and $£ 26,000$ per year, respectively. 
This figure was $£ 19,000$ for those highly educated RMW from new EU member states. Hence, highly educated migrant workers from new EU countries are not directly comparable to high-skilled migrants from non-EEA and Old EU countries and are excluded from the analysis. The mismatch between the educational levels and occupations for nationals of the accession countries working in the UK has been well documented in the previous literature (e.g., Campbell 2013; Clark and Drinkwater 2008; Drinkwater et al. 2009; Vargas-Silva 2014a).

The number of high-skilled RMW in the UK in any given year should have a strong correlation with high-skilled migration inflows of the previous three years. Migration policies should not have a major impact on those high-skilled migrants who have been in the UK for a long period, as many of those originally in need of a permit to work in the UK would have obtained or be close to obtaining indefinite leave to remain in the UK (i.e., no longer subject to the UK visa system).

A key methodological issue for this paper is the definition of skills. In the context of labor markets, relevant skills are difficult to define. In particular, 'soft' skills, such as creativity, communications skills, or empathy, may have an important role to play in many jobs, and therefore in many hiring decisions, but are difficult to measure and quantify. In order to have clear measures of who counts as a high-skilled migrant, this paper defines skills more conventionally. Several indicators in the UK Labour Force Survey are typically used to assess the skill level of a worker: formal qualifications, the skill level defined in the Standard Occupational Classification (SOC) hierarchy and earnings. This paper employs two of these three indicators: qualifications and SOC hierarchy. Separate analysis of earnings data was considered, but this information is only collected in two out of five waves in the UK Labour Force Survey, corresponding to just about $40 \%$ of the respondents of the UK Labour Force Survey who are employees in any given quarter.

Following the previous literature (e.g., Dustmann et al. 2010; Rienzo 2014; VargasSilva 2014b; Wadsworth 2010), this paper uses the age at which the person left fulltime education as a proxy for level of education. The UK Labour Force Survey provides multiple educational attainment measures, but these are based on the UK educational system and may fail to accurately reflect migrants' qualifications. The analysis defines highly educated migrants as those who left full-time education at age 21 or later (which roughly corresponds to at least an undergraduate university degree, but includes individuals with advanced degrees also).

Many highly educated RMW are not doing high-skilled jobs, since migrant workers often downgrade upon their arrival to the country resulting in a mismatch between occupations and educational levels (Aleksynska and Tritah 2013; Currie 2007; Dustmann et al. 2013). This mismatch may be due to the lack of UK specific human capital, poor English skills and non-recognition of qualifications (Johnston et al. 2015). Therefore, we also look at the occupations of migrants. The SOC is a classification of jobs in terms of their skill level and content. The analysis considers those migrants in the top two categories of the 'major occupation groups' as defined in the UK Labour Force Survey ('Managers, Directors and Senior Officials' and 'Professional Occupations') as working in top occupations. Some of the occupations that fall under these two categories include: chief executives, hotel managers, financial managers, scientists, engineers and health professionals. The requirements for an 
occupation to be included by the ONS in these categories are as follows (Office for National Statistics 2010):

- Managers, Directors and Senior Officials: A significant amount of knowledge and experience of the production processes and service requirements associated with the efficient functioning of organizations and businesses.

- Professional Occupations: A degree or equivalent qualification, with some occupations requiring postgraduate qualifications and/or a formal period of experience-related training.

\section{Methodology}

The analysis has two components: estimating actual changes and presenting alternative scenarios. In the discussion of the actual changes, we report the total number of highskilled RMW in the UK and then focus on sub-groups of high-skilled non-EEA and Old EU nationals.

It is not possible to create a perfect alternative scenario of the number of high-skilled RMW without the policy changes. However, it is possible to provide a broad idea of the developments that could have occurred without the policy changes. Two exercises are conducted for this purpose.

First, we do a simple extrapolation of the number of high-skilled RMW in a prerestrictions year. We use the annual growth rate in the number of non-EU and Old EU high-skilled RMW from 2007 to 2008 and the 2007 number as the base year for the extrapolation. This extrapolation provides an estimate for high-skilled RMW in 2010 2013 if the 2007 trend continued.

We use 2007 as the base in order to address possible concerns of the UK being in recession from the end of 2008 to mid-2009. It would be expected for the economic downturn to affect the demand for migrant labor in the UK. For completeness purposes we also include an estimation using 2009 as the base year (i.e., the year before David Cameron became Prime Minister and established the net migration target). The dynamics are similar across base years but we prefer the estimates using 2007 as the base year. RMW are defined as those who have been in the UK for less than three years and using 2008, 2009 or even 2010 as the base year would include a substantial portion of the downturn in the period considered for the definition of RMW.

Second, we conduct a counterfactual exercise in which we 're-weight' the individuals in the UK Labour Force Survey for years 2010 to 2013 in order for them to have similar 'average' characteristics to individuals in the 2007 sample. These characteristics include the workforce share of high-skilled RMW and the relative importance of different sectors of the economy for overall UK employment. This approach has been used extensively in other settings (e.g., Lemieux 2006, Rienzo 2014). Intuitively, this approach answers questions such as the following: How many high-skilled non-EEA RMW would there be in the UK in 2013 if the characteristics of the workforce where the same as in 2007-i.e., when restrictions were not implemented? The re-weighting exercise downweights some individuals and upweights others so that their observable characteristics (age, gender, nationality, education, marital status, occupation) closely resemble those of the 2007 population. 
Again, 2007 is used as the comparison year to avoid the 2008/2009 economic downturn and the introduction of the policies to decrease net migration. The comparison is to the characteristics of the workforce in a pre-downturn, pre-restrictive policies period. Note that by 2012 and 2013 all RMW are post-downturn migrants, while for 2007 all RMW are pre-downturn migrants. For completeness purposes we also report the estimates obtained using 2009 as the comparison year.

In technical terms, let $\omega_{i t}$ be the UK Labour Force Survey sample weight for worker $i$ at time $t\left(t=2010,2011,2012\right.$ or 2013) and $\omega_{i t}^{*}$ be the counterfactual weight for worker $i$ that makes the composition of the population the same as in a base year $s$ (i.e., 2007). The weight $\omega_{i t}$ is calculated by the UK Office for National Statistics, and it is included in the UK Labour Force Survey datasets, but it is necessary to estimate $\omega_{i t}^{*}$. We calculate $\omega_{i t}^{*}$ in two steps. First, we estimate a logit model with pooled data from year $t$ and 2007, having as the dependent variable a dummy for the year $t$, and as controls the characteristics of the workforce, including a dummy variable indicating 'recent high-skilled migrant worker' status, as well as a quadratic in age, interaction terms between age and education, marital status, gender, nationality group and major occupation based on SOC2010 definition. Second, we obtain the predicted probability $\left(P_{i}\right)$ that an individual with certain characteristics is observed in year $t$ rather than in the base year 2007. Then we estimate $\omega_{i t}^{*}$ as:

$$
\omega_{i t}^{*}=\left(\frac{1-P_{i}}{P_{i}}\right) \omega_{i t}
$$

Finally, we estimate the population values using the new weights in (1).

In order to illustrate the usefulness of the re-weighting procedure, we provide the example in Table 2. These are two actual individuals in the sample. Individual A is 33 years old and has 11 years of schooling in 2013. Individual B is 55 years old and has 17 years of schooling in 2013. On average, the individuals in the 2013 population are older and have more years of schooling than those in the 2007 population. This should be reflected in their relative probabilities of being observed in 2013 relative to 2007. That is, we would expect:

$$
\frac{1-P_{B}}{P_{B}}>\frac{1-P_{A}}{P_{A}}
$$

As reported in Table 2, this is actually the case. Therefore, in the re-weighting procedure, the weight of Individual A increases considerably, but the weight of individual $B$ does not change much.

Table 2 Example using the re-weighting procedure

\begin{tabular}{lll}
\hline Variable & Individual A & Individual B \\
\hline Age & 33 & 55 \\
Years of schooling & 11 & 17 \\
UK Labour Force Survey weight $(\omega)$ & 688 & 368 \\
$P_{i} /\left(1-P_{i}\right)$ & 1.32 & 1.06 \\
New weight $\left(\omega^{*}\right)$ & 906 & 391 \\
\hline
\end{tabular}


Likewise, certain high-skilled RMW could be relatively less (more) likely to be observed in 2013 than in 2007 given their overall characteristics, suggesting a lower (higher) value of $P_{i}$ and a higher (lower) value of $\left(1-P_{i}\right)$. These individuals are thus up weighted (down weighted) when $\omega_{i t}$ is replaced by $\omega_{i t}^{*}$. This re-weighting approach is equivalent to propensity score matching. In this case the period $t$ sample is the 'treatment group', while the 2007 sample is the 'control group'. The estimated propensity score is $P_{i}$. See DiNardo, Fortin and Lemieux (1996), DiNardo (2002) and Lemieux (2006) for further discussion of the methodology.

In the same spirit of the propensity score matching, the re-weighting approach does not rely on functional form assumptions. However, the reweighting approach is based on other key assumptions. The methodology is based on the assumption that assignment to the treatment (i.e., the probability to be observed in a specific year) only depends on observable characteristics. That is, the methodology assumes no selection on unobservables. Unlike propensity score matching, there are not specific tests developed for this methodology regarding this assumption. In our analysis, the distribution of unobservable skills/characteristics of individuals within the same level of education and nativity status is assumed to be stable over time. This implies that any self-selection of migrants into the UK is assumed to be time-invariant over the period examined and it is not affected by the recent UK Government policies.

\section{Actual changes}

\subsection{Number of high-skilled RMW}

While evaluating the evidence presented below, it is important to keep in mind that the focus of this paper is on high-skilled 'recently arrived migrant workers,' or RMW, rather than the whole population of high-skilled migrants working or living in the UK. Evidence of a reduction in the number of RMW does not indicate a reduction in the total number of high-skilled migrants working in the UK but just a reduction in the number who arrived recently (i.e., a measure which reflects the recent inflow of migrants).

Panel A of Table 3 reports the total number of high-skilled RMW in the UK in each year from 2010 to 2013, and under slightly different definitions of who counts in this high-skilled group. Column (1) reports numbers for highly educated workers, without distinctions by type of employment. The overall number of highly educated RMW increased from 188,000 in 2010 to 270,000 in 2011, the peak for the period in the table. As explained above, 2011 was the year in which most of the new restrictions to decrease net migration came into effect. The number of high-skilled RMW in 2013 was 242,000, a reduction of 28,000 from 2011 (10\% decrease). As expected, the new policies to decrease net migration have resulted in a smaller number of high-skilled RMW in the UK. However, the reduction is not very large. Looking at those in top occupations and those in top occupations that are also highly educated provides a similar picture: there are less high-skilled RMW in the UK, but the reduction is not big.

The previous discussion suggests that there was a relatively small reduction in the number of high-skilled RMW since 2011. This would suggest that while the UK Government policies may have had some effect on high-skilled migration, the impact was not substantial. But it is important to remember that these policy changes were 
Table 3 High-skilled RMW in the UK (thousands)

\begin{tabular}{llll}
\hline Year & Highly educated & $\begin{array}{l}\text { Top occupations } \\
(\mathbf{1})\end{array}$ & $\begin{array}{l}\text { Highly educated and top occupations } \\
(\mathbf{3})\end{array}$ \\
\hline 2010 & 188 & & 62 \\
2011 & 270 & 79 & 89 \\
2012 & 227 & 103 & 83 \\
2013 & 242 & 94 & 82 \\
& (B) Non-EEA RMW & 97 & \\
2010 & 109 & 49 & 42 \\
2011 & 154 & 65 & 56 \\
2012 & 119 & 60 & 53 \\
2013 & 94 & 44 & 38 \\
& (C) Old EU RMW & & \\
2010 & 33 & 15 & 10 \\
2011 & 51 & 30 & 28 \\
2012 & 50 & 24 & 21 \\
2013 & 78 & 45 & 39 \\
\hline
\end{tabular}

Note: Column (1): highly educated in all types of employment. Column (2): those in the top two main occupation categories, all levels of education. Column (3): highly educated and in the top two major occupation categories.

directed at non-EEA migration. EEA nationals enjoy free movement to the UK and the UK Government cannot impose limitations on their migration.

Panel B of Table 3 presents a similar analysis to Panel A but with a focus only on those RMW from outside the EEA. The overall number of highly educated non-EEA RMW has decreased by close to 39\% since 2011 (from 154,000 in 2007 to 94,000 in 2013). There has been a negative trend in this number since 2011, when policies to reduce net migration to the UK presumably began to have the bulk of their effects. The results are similar for all columns of Table 3.

Panel $\mathrm{C}$ of Table 3 repeats the same analysis but for Old EU nationals. The number of high-skilled Old EU RMW increased from 51,000 to 78,000 in 2013, a 53\% increase. This increase is consistent across all columns.

The increase in Old EU RMW does not come as a surprise. Recent data from national insurance number registrations in the UK show that nationals of Spain and Italy occupied the second and third place in registrations among adult overseas nationals entering the UK in the year to March 2013. Only nationals of Poland, the main country of immigration to the UK since 2004, came ahead of the Spanish and Italian nationals. National insurance number registrations to nationals of Spain and Italy increased by $50 \%$ and $35 \%$, respectively, compared to the previous year (Department of Work and Pensions 2013). Information from the UK International Passenger Survey also suggests a recent surge in Old EU migration to the UK. An estimated 104,000 Old EU nationals arrived to work in the UK in 2013, an increase of 19,000 compared to 2012 (Office for National Statistics 2015).

It is also possible that the dynamics presented above are somehow affected by changes in sub-groups of high-skilled RMW. In order to explore this, Table 4 presents the results if we focus on certain sub-groups of highly educated RMW. Column (1) 
Table 4 Sub-groups of highly educated RMW in the UK (thousands)

\begin{tabular}{llll}
\hline Year & Full time & Employees & Excluding students \\
& $(\mathbf{1})$ & $(\mathbf{2})$ & $(\mathbf{3})$ \\
\hline 2010 & (A) All RMW & & 147 \\
2011 & 138 & 177 & 218 \\
2012 & 208 & 251 & 202 \\
2013 & 183 & 202 & 221 \\
& 197 & 226 & 82 \\
2010 & (B) Non-EEA RMW & & 117 \\
2011 & 76 & 106 & 104 \\
2012 & 109 & 148 & 84 \\
2013 & 91 & 110 & \\
& 75 & 93 & 26 \\
2010 & (C) Old EU RMW & & 46 \\
2011 & 27 & 30 & 46 \\
2012 & 45 & 46 & 72 \\
2013 & 43 & 47 & 75 \\
\hline
\end{tabular}

Note: Column (1) only includes those who are in full time employment. Column (2) only includes those who are employees. Column (3) excludes those who are currently studying. Source: authors' estimates from the UK Labour Force Survey, Q4.

only includes those working full time. It is possible that the restrictions have affected part-time and full-time workers differently. Column (2) only includes individuals who are employees (i.e., excludes those in self-employment). Column (3) excludes those who are currently studying. As explained above, non-EEA students were one of the main targets of the new Government restrictions. Limiting the analysis to the sub-groups does not affect the main result. In all three columns there is a substantial decrease in non-EEA RMW since 2011 and an increase in Old EU RMW.

\section{Alternative scenarios}

In this section we construct several scenarios of the potential dynamics of high-skilled migration to the UK without the new government policy restrictions.

\subsection{Previous trends}

As explained above we start by using the annual growth rate in non-EU and Old EU RMW in the UK for 2007 and project the number of high-skilled RMW assuming those same growth rates for the years after 2007. We also present results using 2009 as the base year. The growth rate of non-EEA highly educated RMW for 2007-2008 was $16 \%$. The growth rate of Old EU highly educated RMW for $2007-2008$ was $-3 \%$. As shown in Figure 2, if those growth rates were to hold for the following years, we would have seen a much greater increase in the number of high-skilled non-EEA RMW and a modest decrease in the number of Old EU RMW. By 2013 the number of non-EEA highly educated RMW would have been 368,000 , almost four times higher than the actual number, and the number of highly educated Old EU RMW would have been about 28,000 less than the actual value. 


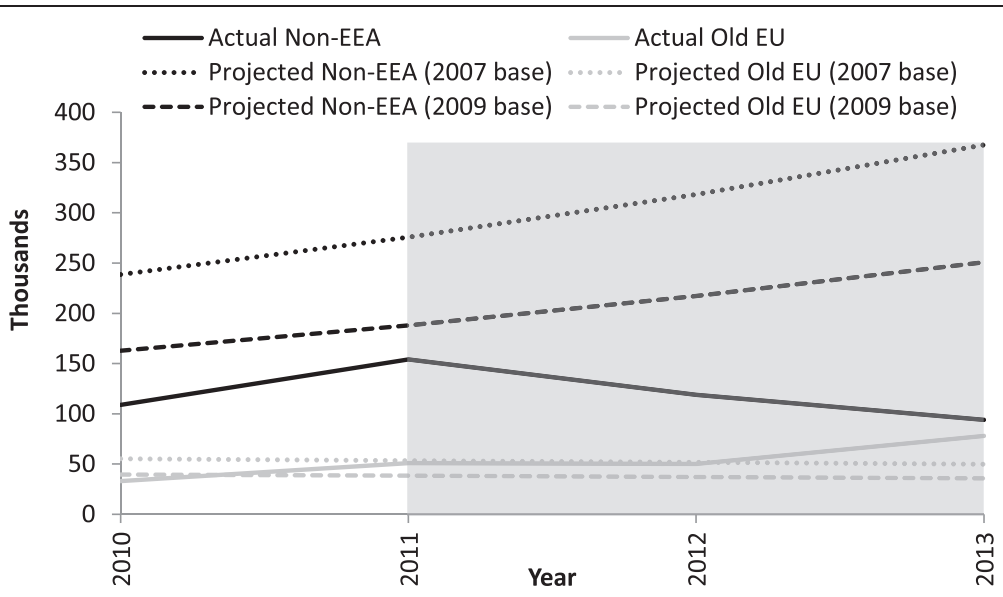

(A) Highly educated RMW

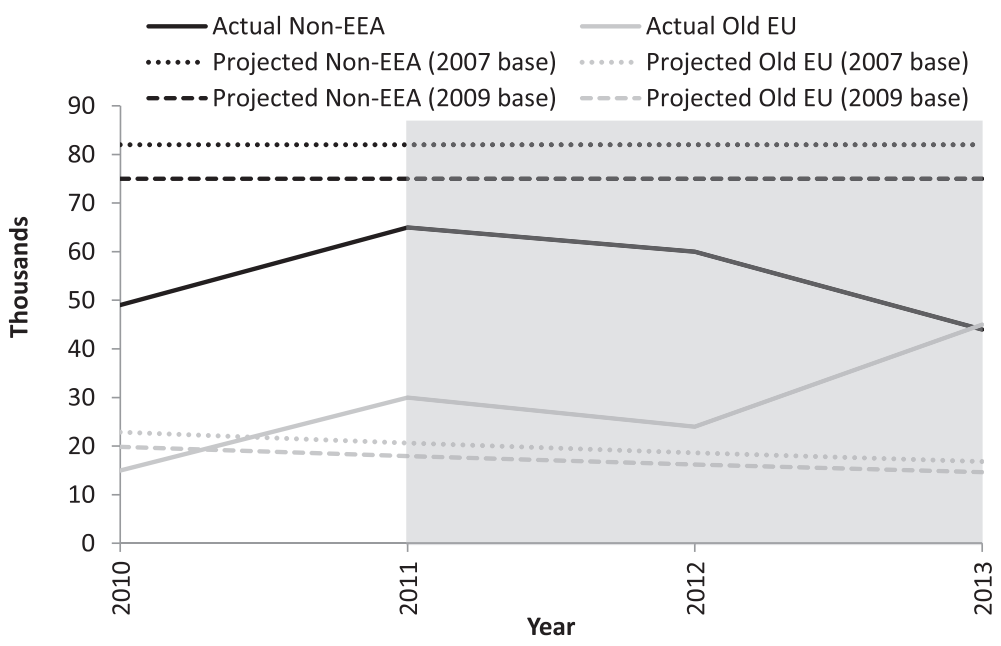

(B) RMW in top occupations

Figure 2 Actual and projected Non-EEA and Old EU high-skilled RMW using trend. (A) Highly educated RMW. (B) RMW in top occupations. Source: Authors' analysis of the UK Labour Force Survey, Q4. Shaded areas indicate the periods in which most policies to decrease net migration were in effect.

The number of non-EEA RMW in top occupations was flat for 2007-2008, while the growth rate of Old EU RMW in top occupations for $2007-2008$ was $-10 \%$. The results suggest that the number of non-EEA RMW in top occupations would have been 38,000 higher if this pattern had continued over the next few years, and the number of Old EU nationals in top occupations would have been 28,000 lower. The main dynamics are similar if we use 2009 instead of 2007 as the base year.

\subsection{Re-weighting procedure}

Table 5 reports the average characteristics of the UK working age population during the 2007-2013 period. In the re-weighting exercise, the working age population of each year from 2010 to 2013 is matched separately with that of 2007. There were about 35 million people of working age in the UK during 2013. Hence, every percentage point in the table roughly accounts to about 350,000 individuals. One interesting trend 
Table 5 Characteristics of the UK working age population

\begin{tabular}{llllll}
\hline & $\mathbf{2 0 0 7}$ & $\mathbf{2 0 1 0}$ & $\mathbf{2 0 1 1}$ & $\mathbf{2 0 1 2}$ & $\mathbf{2 0 1 3}$ \\
\hline & Demographic variables & & & \\
Married & $56.36 \%$ & $54.47 \%$ & $53.84 \%$ & $53.66 \%$ & $52.76 \%$ \\
Age (years) & 37.82 & 37.73 & 37.71 & 37.75 & 37.77 \\
Education (years) & 13.66 & 13.69 & 13.77 & 13.83 & 13.90 \\
Female & $52.54 \%$ & $52.62 \%$ & $52.61 \%$ & $52.54 \%$ & $52.55 \%$ \\
& RMW status & & & & \\
Non-EEA RMW & $0.76 \%$ & $0.49 \%$ & $0.63 \%$ & $0.46 \%$ & $0.38 \%$ \\
Old EU RMW & $0.25 \%$ & $0.16 \%$ & $0.20 \%$ & $0.19 \%$ & $0.32 \%$ \\
Non-EEA highly educated RMW & $0.43 \%$ & $0.30 \%$ & $0.43 \%$ & $0.33 \%$ & $0.26 \%$ \\
Old EU highly educated RMW & $0.18 \%$ & $0.09 \%$ & $0.15 \%$ & $0.14 \%$ & $0.22 \%$ \\
Managers and Senior Officials & Major occupation group & & & \\
Professional Occupations & $11.31 \%$ & $11.14 \%$ & $7.01 \%$ & $7.22 \%$ & $7.31 \%$ \\
Associate Professional and Technical & $9.91 \%$ & $10.37 \%$ & $14.05 \%$ & $14.48 \%$ & $14.88 \%$ \\
Administrative and Secretarial & $11.05 \%$ & $10.78 \%$ & $10.12 \%$ & $10.43 \%$ & $10.33 \%$ \\
Skilled Trades Occupations & $8.38 \%$ & $7.59 \%$ & $7.84 \%$ & $7.61 \%$ & $7.56 \%$ \\
Personal Service Occupations & $8.43 \%$ & $7.65 \%$ & $8.05 \%$ & $7.81 \%$ & $7.95 \%$ \\
Sales and Customer Service Occupations & $5.82 \%$ & $6.22 \%$ & $6.37 \%$ & $6.46 \%$ & $6.67 \%$ \\
Process, Plant and Machine Operatives & $5.38 \%$ & $4.72 \%$ & $4.58 \%$ & $4.62 \%$ & $4.59 \%$ \\
Elementary Occupations & $8.74 \%$ & $8.25 \%$ & $8.09 \%$ & $8.09 \%$ & $8.08 \%$ \\
Not in employment & $25.21 \%$ & $27.80 \%$ & $27.91 \%$ & $27.18 \%$ & $26.64 \%$ \\
\hline Source aut & & & &
\end{tabular}

Source: authors' estimates from the UK Labour Force Survey, Q4.

regarding high-skilled work is that 'Professional Occupations' have become more important over time, while 'Managerial and Senior Officials' occupations have become less important.

As explained above the first step in the construction of the counterfactuals is to estimate separate logit models with pooled data from year 2007 and each of the following years. An additional file 1, which accompanies this paper, contains the results (i.e., odd ratios and logit coefficients) from each of these estimations. Using the information from the logit models, it is possible to create the counterfactuals. Figure 3 shows the results of the re-weighting procedure. As with the extrapolation, it is possible to observe that if the characteristics of the UK workforce (including the likelihood of being a high-skilled RMW) were held at their 2007 means, the number of non-EEA highly educated RMW would have been much higher in 2013 (102,000 higher), and the number of Old EU high-skilled RMW would have been about the same. Looking at those in top occupations, this number would have been 25,000 higher for non-EEA RMW and 14,000 lower for Old EU RMW. Moreover, changing the comparison year to 2009 does not affect the main dynamics.

\section{High-skilled RMW as a share of all RMW}

It is also possible to examine if the restrictions have resulted in RMW being more likely to be high skilled. As suggested by Table 6, despite the reduction in absolute numbers of highly educated RMW during the 2007-2103 period, the RMW 


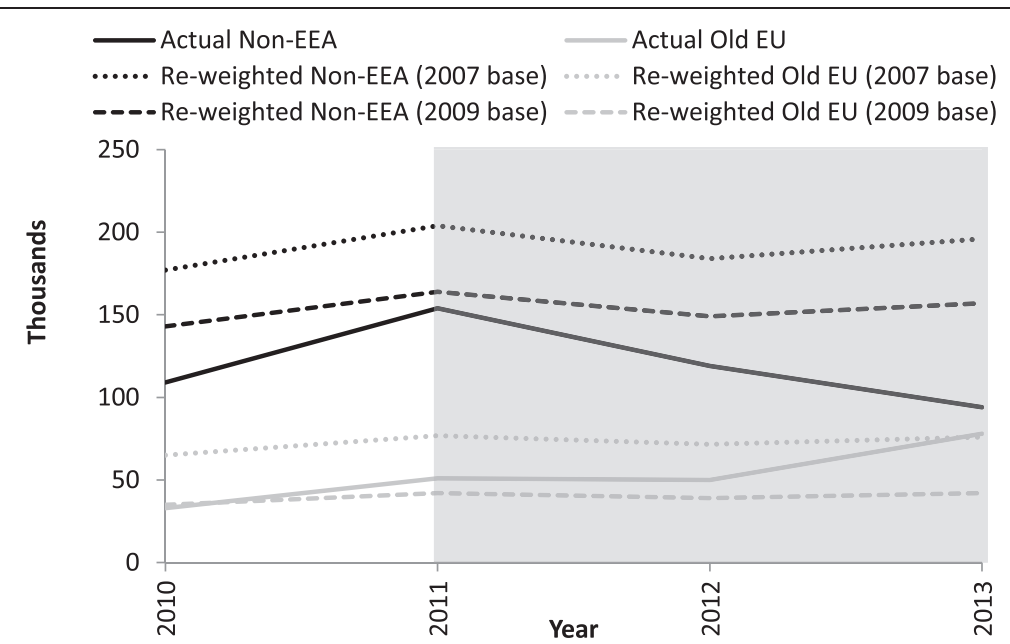

(A) Highly educated RMW

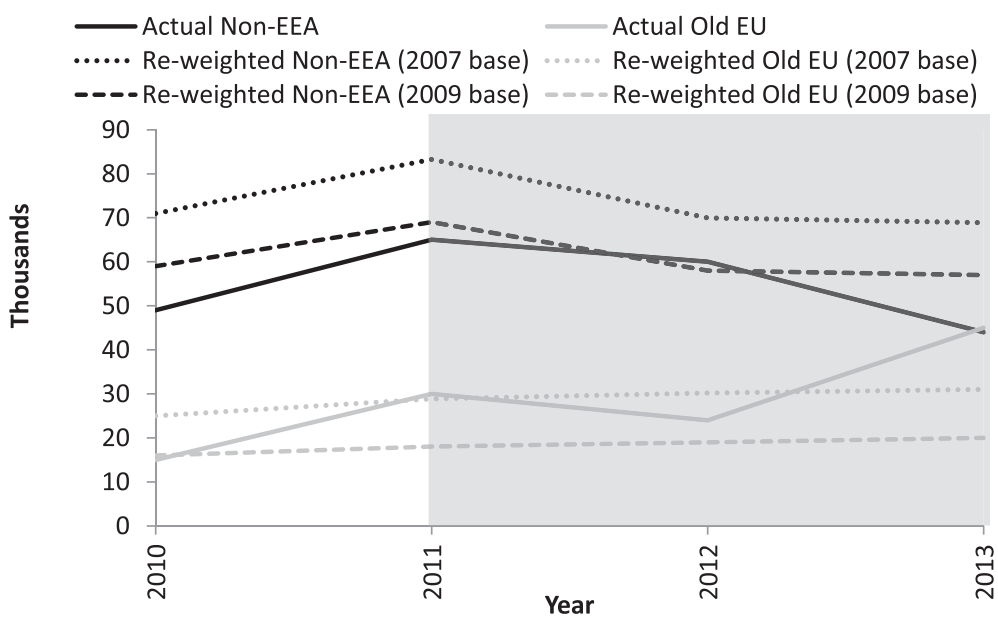

(B) RMW in top occupations

Figure 3 Actual and re-weighted Non-EEA and Old EU high-skilled RMW. (A) Highly educated RMW.

(B) RMW in top occupations. Source: Authors' analysis of the UK Labour Force Survey, Q4. Shaded areas indicate the periods in which most policies to decrease net migration were in effect.

Table 6 Share of RMW which is highly educated

\begin{tabular}{|c|c|c|c|c|c|}
\hline Year & $\begin{array}{l}\text { Highly educated } \\
\text { (1) }\end{array}$ & $\begin{array}{l}\text { Top occupations } \\
\text { (2) }\end{array}$ & $\begin{array}{l}\text { Full time } \\
\text { (3) }\end{array}$ & $\begin{array}{l}\text { Employees } \\
(4)\end{array}$ & $\begin{array}{l}\text { Excluding students } \\
\text { (5) }\end{array}$ \\
\hline & (A) All RMW & & & & \\
\hline 2007 & $50 \%$ & $76 \%$ & $48 \%$ & $50 \%$ & $47 \%$ \\
\hline \multirow[t]{2}{*}{2013} & $60 \%$ & $85 \%$ & $60 \%$ & $62 \%$ & $59 \%$ \\
\hline & (B) Non-EEA RMW & & & & \\
\hline 2007 & $58 \%$ & $75 \%$ & $56 \%$ & $58 \%$ & $55 \%$ \\
\hline \multirow[t]{2}{*}{2013} & $68 \%$ & $87 \%$ & $67 \%$ & $70 \%$ & $66 \%$ \\
\hline & (C) Old EU RMW & & & & \\
\hline 2007 & $70 \%$ & $75 \%$ & $70 \%$ & $70 \%$ & $69 \%$ \\
\hline 2013 & $69 \%$ & $87 \%$ & $73 \%$ & $68 \%$ & $70 \%$ \\
\hline
\end{tabular}

Note: Column (1): highly educated in all types of employment. Column (2): highly educated and in the top two major occupation categories. Column (3): same as Column (1) but only includes those who are in full time employment. Column (4): same as Column (1) but only includes those who are employees. Column (5): same Column (1) but excludes those who are currently studying. Source: authors' estimates from the UK Labour Force Survey, Q4. 
population has become more educated in its composition. The share of all RMW who are highly educated has increased from $50 \%$ in 2007 to $60 \%$ in 2013 . This suggests that the reduction in 'non-high skilled' migration has been greater than the reduction in high-skilled migration. This increase was driven by a rise in the proportion of non-EEA RMW which is highly educated from $58 \%$ to $68 \%$. The proportion of Old EU RMW which is highly educated has remained stable over time at about $70 \%$.

Figure 4 provides counterfactual estimates of the share of all RMW which would have been highly educated if the UK workforce of 2013 had the same characteristics of that of 2007. In all cases RMW would have been less likely to be highly educated. The difference between the actual and counterfactual estimate for nonEEA nationals is 8 percentage points, while the difference is 3 percentage points for Old EU nationals.

\section{Conclusion and policy implications}

The main goal of the UK Government's migration policy since 2010 has been to decrease net migration to less than 100,000 migrants per year by the 2015 General Election. According to the latest net migration estimate, this goal will not be achieved. This paper contributes to the existing literature by exploring the recent policies of the UK Government to analyze the consequences of pursuing a migration target in a context in which discretionary power is limited. The results suggest that policies to decrease net migration were accompanied by a reduction in non-EEA high-skilled RMW and an increase in EEA high-skilled RMW. This is consistent with the fact that UK Government policy changes to make migration more restrictive have been directed towards non-EEA nationals and include the restriction and closing of routes intended for high-skilled migrants. Counterfactual estimates suggest that there would have been more non-EEA high-skilled RMW and fewer Old EU high-skilled RMW in the UK in 2013 with pre-policies conditions.

This finding has important implications for migration policymaking within an area of free movement of labor, such as the EEA. In this case migration involves elements over which the government has varying levels of influence. When it comes to migration of

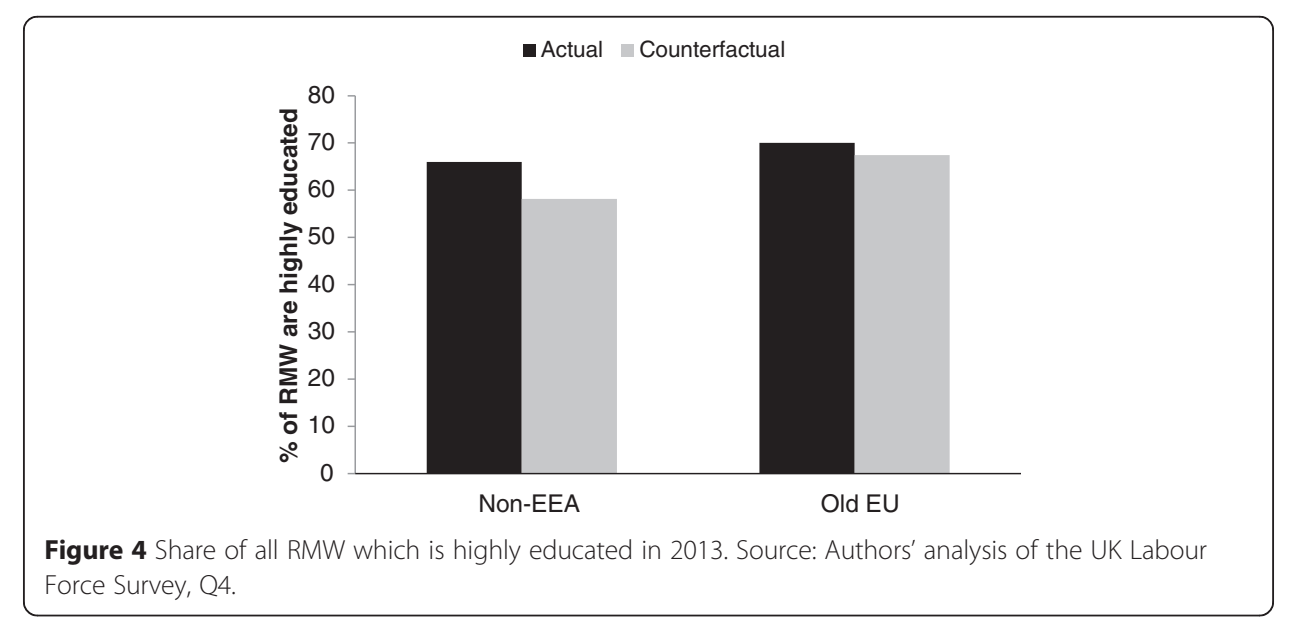


non-EEA nationals, the government has a considerable degree of control. But the government cannot control the immigration and emigration of EEA nationals. As such, efforts directed at reducing the migration from those groups that the government can control may lead to increases in those groups that the government cannot control (i.e., 'balloon effect'). This paper does not prove beyond any doubt that the effect is the consequence of the recent UK Government policies, but it shows that this is a possibility that is consistent with the data and worthy of further investigation and consideration by policymakers.

\section{Appendix: Details of main migration policy changes}

Closing Tier 1 general: The Tier 1 general category was the main route for non-EEA high-skilled labor migration to the UK without a job offer under the UK Points Based System. It opened in 2008 as a replacement for the Highly Skilled Program. Close to 14,000 visas were issued under the Tier 1 category in 2010 (Blinder 2013). This category was closed in 2011. Now most non-EEA nationals migrating to the UK for work need a job offer. One of the justifications for closing the Tier 1 general category was that while those coming by this route were highly educated, a share of those in this unrestricted category was doing unskilled work (29\% according to UK Border Agency (2010)). We address this possible mismatch between education and occupations in our analysis by using alternative definitions of a high-skilled migrant worker.

Cap on Tier 2 general: The Tier 2 general category is the main route for non-EEA migration to the UK for work reasons with a job offer. In 2011 the UK Government introduced a cap of 20,700 to the number of non-EEA nationals who can apply under this category. Intra-company transfers are not included under the cap. Since the introduction of this cap, the number of visas issued under this category has been substantially lower than the limit, suggesting than the cap is 'non-binding.' This category was also limited to those in 'graduate' level occupations based on the Standard Occupational Classification (see explanation in Section 3), a limitation which could have a greater effect on numbers. The migrant does not necessarily need to hold a graduate qualification, but the job (i.e., vacancy) must be in the graduate occupation list.

Restrictions on student migration: Since 2011 the UK Government has added multiple checks for international students' compliance with visa rules, establishing restrictions on permission to work for international students and limiting the entitlement to bring dependents with them. The government also closed the Tier 1 Post-Study Work route, which allowed non-EEA university students to remain in the UK and work for two years after graduation. There were no earnings or employment conditions requirements.

Restrictions on family migration: Since 2012 the UK Government has made it more difficult for UK nationals and settled migrants to bring a non-EEA spouse or children from abroad. This includes increasing the minimum income threshold to bring nonEEA partners and children to the UK and additional restrictions such as the need to demonstrate English proficiency. Recent estimates suggest that about half of British nationals are now unable to sponsor a non-EEA spouse into the UK (Markaki and Vargas-Silva, 2014). 


\section{Additional file}

\section{Additional file 1: Regression results.}

\section{Competing interests}

The IZA Journal of European Labor Studies is committed to the IZA Guiding Principles of Research Integrity. The authors declare that they have observed these principles.

\section{Acknowledgement}

Thanks to Scott Blinder, Yvonni Markaki, Rob McNeil, Jonathan Portes, Martin Ruhs, Isabel Ruiz, Jonathan Wadsworth, an anonymous referee and the editor for helpful comments and suggestions in earlier versions of this paper. Targeting Migration with Limited Control: The Case of the UK and the EU.

Responsible editor: Martin Kahanec

\section{Author details}

${ }^{1}$ National Institute of Economic and Social Research, 2 Dean Trench Street, Smith Square, London SW1P 3HE, UK.

${ }^{2}$ Centre on Migration, Policy and Society, University of Oxford, 58 Banbury Road, Oxford OX2 6QS, UK.

Received: 29 December 2014 Accepted: 9 April 2015

Published online: 10 August 2015

\section{References}

Aleksynska M, Tritah A (2013) Occupation-education mismatch of immigrant workers in Europe: Context and policies. Econ Educ Rev 36:229-244

Bach S (2010) Managed migration? Nurse recruitment and the consequences of state policy. Ind Relat J 41(3):249-266 Blinder S (2013) Non-EU labor migration to the UK. COMPAS, Oxford University, UK, August, Migration Observatory briefing Blinder S (2014) UK public opinion toward immigration: Overall attitudes and level of concern. COMPAS, Oxford University, UK, July, Migration Observatory briefing

Campbell S (2013) Over-education among A8 migrants in the UK, Department of Quantitative Social Science, University of London, Working Paper No. 13-09

Chartered Institute of Personnel and Development (2014) The growth of EU labor: Assessing the impact on the UK labor market. CIPD, London

Chartered Institute of Personnel Development (2011) Labor market outlook - Summer 2011. CIPD, London

Clark K, Drinkwater S (2008) The labor-market performance of recent migrants. Oxf Rev Econ Policy 24(3):495-516

Clark K, Drinkwater S (2014) Labour migration to the UK from Eastern partnership countries. IZA Journal of European Labor Studies 3(15). http://www.izajoels.com/content/3/1/15

Currie S (2007) De-skilled and devalued: The labor market experience of Polish migrants in the UK following EU enlargement. Int J Comp Labor Law Ind Relat 23(1):83-116

Department of Work and Pensions (2013) National Insurance Number Allocations to Adult Overseas Nationals Entering the UK - Registrations to March 2013. DWP, London

DiNardo J (2002) Propensity score reweighting and changes in wage distributions, Working Paper, University of Michigan., Available at http://www-personal.umich.edu/ jdinardo/bztalk5.pdf

DiNardo J, Fortin N, Lemieux T (1996) Labor market institutions and the distribution of wages, 1973-1992: A semiparametric approach. Econometrica 64(5):1001-1044

Drinkwater S, Robinson C (2013) Welfare participation by immigrants in the UK. Int J Manag 34(2):100-112

Drinkwater S, Eade J, Garapich M (2009) Poles apart? EU enlargement and the labor market outcomes of immigrants in the United Kingdom. Int Migr 47(1):161-190

Dustmann C, Frattini T (2014) The fiscal effects of immigration to the UK. Econ J 124(580):F593-F643

Dustmann C, Glitz A, Vogel T (2010) Employment, wages, and the economic cycle: Differences between immigrants and natives. Eur Econ Rev 54(1):1-17

Dustmann C, Frattini T, Preston I (2013) The effect of immigration along the distribution of wages. Rev Econ Stud $80(1): 145-173$

Home Office (2010) Limit on non-EU workers. Home Office News Story., Available at: https://www.gov.uk/government/ news/limit-on-non-eu-workers

Home Office (2011a) Migration Permanent Limit (Tier 1 and Tier 2): Impact Assessment. Home Office, London

Home Office (2011b) Reform of the Points Based Student (PBS) Immigration System: Impact Assessment. Home Office, London

Home Office (2012) Changes to Family Migration Rules: Impact Assessment. Home Office, London

Hussein S (2014) Hierarchical challenges to transnational social workers' mobility: The United Kingdom as a destination within an expanding European Union. Br J Soc Work 44(suppl 1):i174-i192

Johnston R, N Khattab, Manley D (2015) East versus West? Over-qualification and earnings among the UK's European migrants. J Ethn Migr Stud 41(2):196-218

Lemieux T (2006) Increasing residual wage inequality: Composition effects, noisy data, or rising demand for skill? Am Econ Rev 96(3):461-498

Lemos S, Portes J (2013) New Labour? The effects of migration from Central and Eastern Europe on unemployment and wages in the UK. The B.E. J Econ Anal Policy 14(1):299-338

Markaki Y, Vargas-Silva C (2014) Love and money: how immigration policy discriminates between families. The Conversation., Available at: http://theconversation.com/love-and-money-how-immigration-policy-discriminates-betweenfamilies-34253 Accessed December 6, 2014 
Migration Advisory Committee (2010) Limits on Migration: Limits on Tier 1 and Tier 2 for 2011/12 and Supporting Policies. Home Office, London

Migration Advisory Committee (2012) Limits on Migration: Limit on Tier 2 (General) for 2012/13 and Associated Policies. Home Office, London

Office for National Statistics (2010) SOC2010 Volume 1 Structure and Descriptions of Unit Groups. ONS, London

Office for National Statistics (2015) Migration Statistics Quarterly Report, February 2015. ONS, London

Rienzo C (2014) Residual wage inequality and immigration in the USA and the UK. LABOR 28(3):288-308

Rienzo C, Vargas-Silva C (2014) Migrants in the UK: An overview, Migration Observatory briefing, COMPAS, Oxford University, UK, December

Ruhs M, Anderson B (2010) Introduction. In: Ruhs M, Anderson B (eds) Who Needs Migrant Workers? Labour shortages, immigration, and public policy. Oxford University Press, Oxford

Scullion L, Pemberton S (2010) The implications in North West England of the migrant cap on non-EU workers. A case study of the health and social care sector." Report for Migrant Workers North West

Scullion L, Pemberton S (2015) "The UK migrant cap, migrant mobility and employer implications. Int Migr 53:291-302 UK Border Agency (2010) International Group. Points Based System Tier 1: An Operational Assessment. Home Office, London Vargas-Silva C (2014a) EU migration to the UK: Trends and impacts. Intereconomics 49(3):123-128

Vargas-Silva C (2014b) High skilled migrant workers and the UK business cycle. Population Space Place. doi: 10.1002/psp.1867.

Wadsworth J (2010) The UK labor market and immigration. Natl Inst Econ Rev 213:R35-R42

Submit your manuscript to a SpringerOpen ${ }^{\mathcal{O}}$ journal and benefit from:

- Convenient online submission

- Rigorous peer review

- Immediate publication on acceptance

- Open access: articles freely available online

- High visibility within the field

- Retaining the copyright to your article

Submit your next manuscript at $>$ springeropen.com 